\title{
JAOA/AACOM
}

\section{Empathy in Medicine \\ Cultivating an Empathetic Professional Identity in Osteopathic Medical Students Through Service Learning: A Qualitative Analysis of Reflective Essays}

Leanne M. Chrisman-Khawam, MD, MEd; Joel A. Manzi, OMS III

From the Department of

Social Medicine (Dr Chrisman-Khawam) at the Cleveland Campus of the Ohio University Heritage College of Osteopathic Medicine in Warrensville Heights (Student Doctor Manzi).

Financial Disclosures: None reported.

Support: None reported.

Address correspondence to Joel A. Manzi, OMS III, Ohio University Heritage College of

Osteopathic Medicine, 4810 Warrensville Center Rd, Warrensville Heights, $\mathrm{OH} 44122-7024$.

Email: jm546616@ohio.edu Submitted April 19, 2019; revision received July 10, 2019; accepted July 15, 2019.
Context: The role of professional identity development has been established as a significant element of the "hidden curriculum" in medical education. While most programs do not contain explicit instruction on that topic, service learning initiatives are a popular trend in medical education that offer medical students early clinical experience and an opportunity to develop professional identity. Through intentional reflective practices, service learning can also promote empathy development, a critical component missing from current models.

Objective: To determine the role of service learning participation on the development of empathy and professional identity among osteopathic medical students.

Methods: Using a grounded theory method, the authors analyzed reflective essays from students who voluntarily participated in a service learning project that provided medical care to patients who are homeless. Essays were completed within 1 week of volunteer experience.

Results: The authors collected and analyzed 64 reflective essays from 55 students in this study. A review of the 64 texts yielded 5 coding domains and several subdomains. The codes revealed 4 major themes: (1) incoming attitudes, (2) transformative experiences, (3) empathy development, and (4) professional identity formation.

Conclusions: Structured service learning experiences provide students with an opportunity to develop an empathetic professional identity in the preclinical stage of medical education. This form of volunteer service is a transformative experience that challenges students' incoming perceptions and leads to the development of both empathy and professional identity.

J Am Osteopath Assoc. 2020;120(4):263-272

doi:10.7556/jaoa.2020.043

Keywords: empathy development, medical education, professional identity, service learning

ervice learning opportunities represent a popular trend in medical education that aims to provide students with clinical care experience early in the educational process. ${ }^{1-3}$ In response to increased demand from students and positive responses 
from communities, many medical schools are providing opportunities for students to participate in service learning projects. ${ }^{4-7}$ Whether voluntary or required as a part of the curriculum, many of these projects target an underserved portion of the community, including patients who are elderly, uninsured, or homeless, or patients with chronic diseases. ${ }^{2,8,9}$

One particularly common service learning project is the student-run free clinic model. In these clinics, medical students work under the supervision of residents and attending physicians to administer medical services at no cost to patients who have a low income or are homeless. ${ }^{3,5,10-12}$ These clinics provide a substantial amount of care in the community and the majority of care for people who are homeless. ${ }^{2}$ In addition to providing much-needed primary and preventive health care to patients, free clinics give medical students the opportunity to model patient-physician relationships, foster interprofessional relationships, and develop an identity as a physician. ${ }^{10,11,13-15}$ Because of their dual nature as a community resource and an educational tool, these clinics are being recognized as powerful training grounds for future physicians.

Professional identity development models have been discussed thoroughly in the literature. ${ }^{16-23}$ Although varied in their definitions, authors ${ }^{17,24}$ agree that professional identity development is a major part of the "hidden curriculum" of medical education. While rarely presented in traditional curricula, medical students are expected to successfully navigate the transition between student and physician without explicit instruction. ${ }^{24-27}$ Typically, students are expected to glean this understanding from observing attending or resident physicians during clerkships or through limited patient interactions in the preclinical phase of education. Students who do not develop a positive professional identity early enough in their careers are more likely to feel inadequately prepared to meet patient needs, display symptoms of burnout, have professionalism gaps, or face medical malpractice claims. $^{27-30}$
Current models of professional identity development highlight 3 major components: an internal identity, an interpersonal identity, and an institutional identity. ${ }^{16}$ Within each component, the element of identity must be matured with intentional practices that promote healthy professional identity development, such as socialization, mentorship, and reflective practice. ${ }^{10,16,20,24-26}$ "Ingroup" relationships between medical students as well as "outgroup" relationships between friends and family members contribute to identity development. ${ }^{17,23,27,28}$ Mentorship provided by resident and attending physicians has also been cited as an important factor in professional identity formation. ${ }^{24-28,31}$ In addition to externally focused relationships, reflective practices such as journaling have been shown to have a large effect on professional identity development. ${ }^{10,19,32} \mathrm{Niem}^{20}$ suggested that the quality of reflection in terms of introspection and conclusions drawn correlates with the level of personal identity development.

Healthy patient-physician relationships are central to successful health care delivery and require physicians to develop a strong professional identity, of which the cornerstone is empathy. ${ }^{29,33-37}$ Within the realms of physician empathy, a working definition has been stated as, “...[a] physician's understanding of the patient and verbal and nonverbal communication of the physician resulting in a helpful therapeutic action." 38 The aspects of empathy can largely be classified as either cognitive or affective and correspond to self-directed actions or external actions. ${ }^{39}$ Most research on the integration of empathy and medical education has used either the Interpersonal Reactivity Index or the Jefferson Scale of Physician Empathy. ${ }^{36,40}$ Both provide quantitative scores of overall empathy and subset scores correlating to different dimensions of empathy. In the Interpersonal Reactivity Index, empathy is subdivided into 4 components: perspective-taking, fantasy, empathetic concern, and personal distress. ${ }^{40}$ The Jefferson Scale of Physician Empathy expresses similar ideas in terminology related to the patient-physician 
experience: perspective-taking, compassionate care, and standing in the patient's shoes. ${ }^{36,39}$

Empathy as a whole is largely missing from the leading models of professional identity development. Several studies ${ }^{41-44}$ have shown that levels of physician empathy are inversely related to the amount of medical education received. Most studies examining medical student empathy have been conducted with allopathic students, and the limited studies ${ }^{45-48}$ examining osteopathic medical students display similar declines in empathy with increasing levels of training. The current study aimed to determine the role that service learning projects, such as student-run free clinics for people who are homeless, have in the development of osteopathic medical student empathy and professional identity.

\section{Methods}

\section{Setting and Participants}

The Doctors on the Streets (DOTS) program was initially conceived as a resident-run medical outreach to people who are homeless in urban neighborhoods of Cleveland, Ohio. Over time, this outreach evolved into a seasonal clinic housed within an emergency cold weather shelter and Catholic community center. During weekly clinics, patients were provided free primary care evaluations, blood pressure and glucose monitoring, seasonal flu vaccines, wound care, and osteopathic manipulative treatment (OMT). Most volunteers were from local medical schools and allied health programs. Participation in this program was completely voluntary, and recruitment was advertised through campus extracurricular clubs and student organizations. Students were not offered any incentive for participating in this program. Care teams typically consisted of a premedical student, 2 to 4 medical students, a resident, and an attending physician. At the conclusion of each clinic, the care team met to discuss meaningful personal encounters and reflect on the experience. After this discussion, students and residents were encouraged to submit a written reflection to the program director (L.M.C.) regarding their experience. Students were encouraged to reflect on personal narratives and relationships by including the following: what they saw, what emotions they felt, the effect of their interactions, the importance of community service on their personal development, and how that experience will affect their future care of patients.

\section{Data Collection and Analysis}

Student volunteers submitted written reflective essays electronically to the program director via email as part of the educational objectives of the service learning project. For this retrospective investigation, all reflective essays submitted over 2 academic years were reviewed. Submissions were cleaned of identifiable information, formatted uniformly, and saved as separate files prior to analysis. Cleaned submissions were then analyzed via a grounded theory method by a blinded researcher (J.A.M.) using NVivo, version 11.4.11064 (QSR International). The first reading of the texts yielded several broad themes, which were then subdivided into a specific coding schema agreed upon by both researchers after an independent review of the texts. Submissions were then thematically coded using the devised schema as outlined in Table 1. Key illustrative quotes from each theme were also identified. The coded segments were organized into larger conceptual categories that allowed the researchers to form the pedagogical theory described in this article. All reflective essays were read and reviewed by both researchers. This investigation was reviewed and approved by the institutional review board at Ohio University.

\section{Results}

A total of 64 reflective essays were collected and analyzed as part of this study from 55 osteopathic medical students (OMSs) and other allied health professional students. Twenty OMS I (36.4\%), 21 OMS II (38.2\%), 8 OMS III or higher $(14.5 \%)$, and 6 other allied health professions students $(10.9 \%)$ were represented in this 
Table.

Coding Schema and Hierarchy of Recurring Themes in the Reflective Essays Written by Student Volunteers Participating in a Service Learning Program

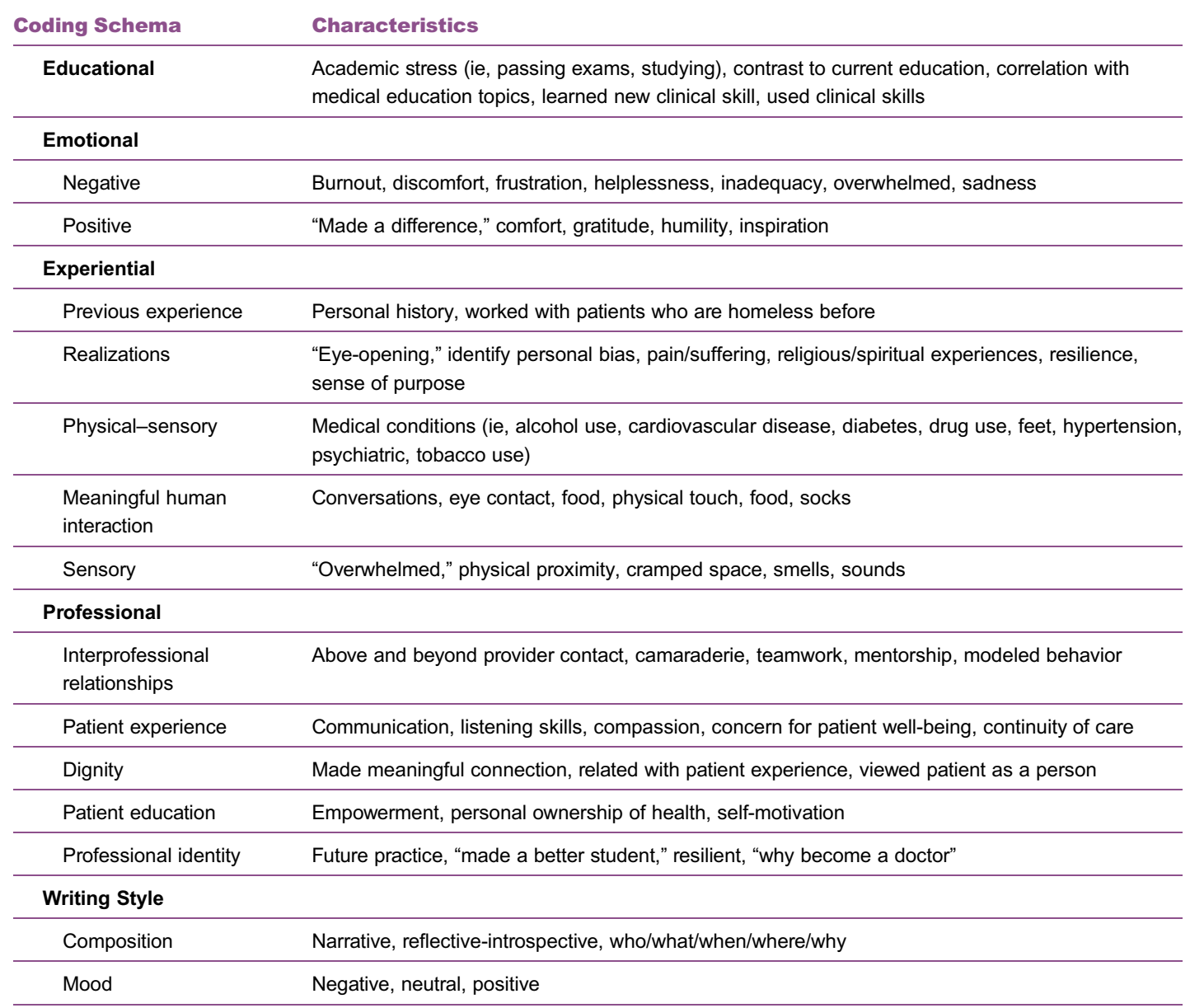

study. As a result of the analysis, 5 major coding domains were identified. Within each domain, there were several subdomains that further differentiated the reflective essays. The hierarchy and usage frequency of the domains and subdomains is illustrated in Table 1. A synthesis of the coding schema identified 4 major themes: (1) incoming attitudes, (2) transformative experiences, (3) empathy development, and (4) professional identity formation. A visual representation of the transformation of the coding, domains, and thematic elements can be seen in Figure 1.

\section{Incoming Attitudes}

Before participating in this program, many students acknowledged that they had little to no experience interacting with patients who are homeless. In addition to being unfamiliar with the patient base, many students reported descriptive, multifocal sensory imagery that left them feeling overstimulated and overwhelmed when they first entered the clinic. Many of the students experienced feelings of frustration, embarrassment, and inadequacy when performing basic clinical skills. Even more concerning, several students, 
First Order Coding

- Previous experience with patients who are homeless

- Sensory/overwhelmed

- Inadequacy/discomfort

- Symptoms of burnout

- Clinical skills
Thematic Domains

Stage of Professional Identity Development

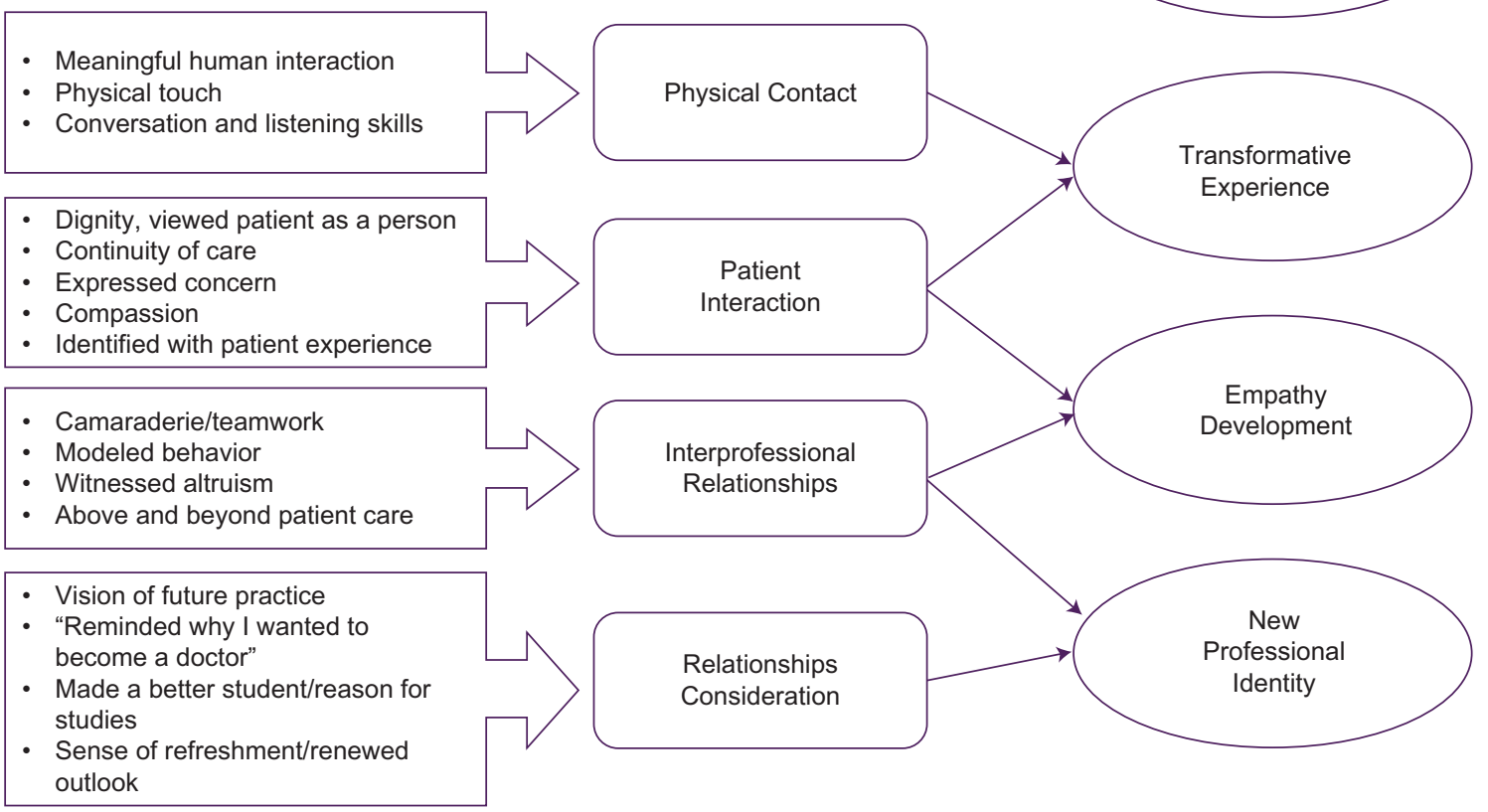

Figure 1.

A visual representation of the transformation of the coding, domains, and thematic elements that were found throughout the reflective essays written by students who volunteered for the Doctors on the Streets service learning program.

though early in their medical education, were already showing serious signs of burnout. A sample of the students' responses describing their initial feelings and attitudes when they began the program is provided in Figure 2.

\section{Transformative Experiences}

The students frequently mentioned their opportunity to perform basic patient care. Several students remarked that it was the first time that they had been able to use their clinical skills outside the classroom, and many reported a sense of pride and accomplishment at learning a new skill set. Using these clinical skills allowed students to have meaningful interactions with their patients, and many students relayed a sense of intimacy with their patients that stemmed from close physical contact. Through the use of basic examination skills and hands-on application of OMT, students stated that physical touch was their first source of meaningful interaction with patients. Additionally, conversation was the second most common source of meaningful interaction cited. Many students remarked that patients seemed more appreciative of their listening ability than their medical skills. A sample of student responses describing their experiences at DOTS is provided in Figure 2.

\section{Empathy Development}

After these exchanges, many students shifted into a more introspective domain in evaluating their 
experience and realized a sense of connection to their patients on a human level. Several students shared that at some point in the clinic, they had identified with a part of a patient's experience or tried to put themselves in the patient's shoes. As a result of these experiences, a strong motif of empathy emerged; many students took ownership of their relationships with their patients, expressing a need for partnership and continuity of care to best provide for their patients. A sample of the students' responses that displayed empathy development as a result of their experience at DOTS is provided in Figure 2.

\section{Professional Identity}

Working in the clinic provided students with an early exposure to team-based health care. Many students noted that they felt a sense of camaraderie among their volunteer teams that contrasted to the isolation they had experienced in traditional educational settings. At the clinic, students were able to work in conjunction with family medicine residents, and several students remarked that the residents were examples of physicians they hoped to become. The residents modeled empathetic behavior by providing assistance that was beyond the standard of care, which led students to reflect on their future careers and practice. Many students remarked that this experience helped them to reconnect with why they initially wanted to become doctors and the role they might fill in their own community. Actively using their clinical skills and interacting with patients led to an increased sense of purpose and provided value to the students' educational pursuits. As many students reported stress and fatigue related to schooling and personal situations, they also reported feeling refreshed and renewed after their volunteer participation. Students who initially reported burnout symptoms also noticed a marked change in their outlook on their education and future career. A sample of the students' responses that described an increased sense of professional identity based on their experience at DOTS is provided in Figure 2.

\section{Discussion}

Students were not prompted to describe empathy or coached on the models of physician empathy before submitting their reflective essays. However, the themes identified in the essays align with each of the subsets of empathy as described in the literature. ${ }^{36}$ The concepts of perspective-taking, compassionate care, empathetic concern, and personal distress were frequently cited by students as integral parts of their volunteer experience. Almost all reflective essays contained at least 1 element or subset of empathy. These themes of empathy arose organically from the students' engagement with the reflective process.

Of particular interest were the students' writings regarding personal distress. This component of empathy is negatively related to measures of social function and not included in all models of empathy. ${ }^{40}$ Many students reported distress about working in an unfamiliar setting, their own inadequacies as physicians, and the intensity of their interactions with patients. The dissonance between the medical school environment and the clinical environment was highlighted by several students. When left unchecked, these experiences of personal distress can lead to anxiety and discomfort in emotional social settings and decreased self-esteem. In this intervention, those feelings were not left unchecked. Intentional reflective practices, collaborative care models, and mentorship from resident and attending physicians gave students the tools necessary to navigate these feelings of distress and navigate their own empathetic and professional development.

Although no formal mechanisms for teaching empathy have been identified, it appears that empathy development is at least partially influenced by the external environment. Creating an intentional opportunity for students to participate in the care of patients who are homeless may add to empathy and professional identity formation through the promotion of altruism, volunteerism, student well-being, and intentional reflection. Providing patient care early in the educational process also provides a major contribution to the formation of a positive professional identity. ${ }^{8,44}$ Several 


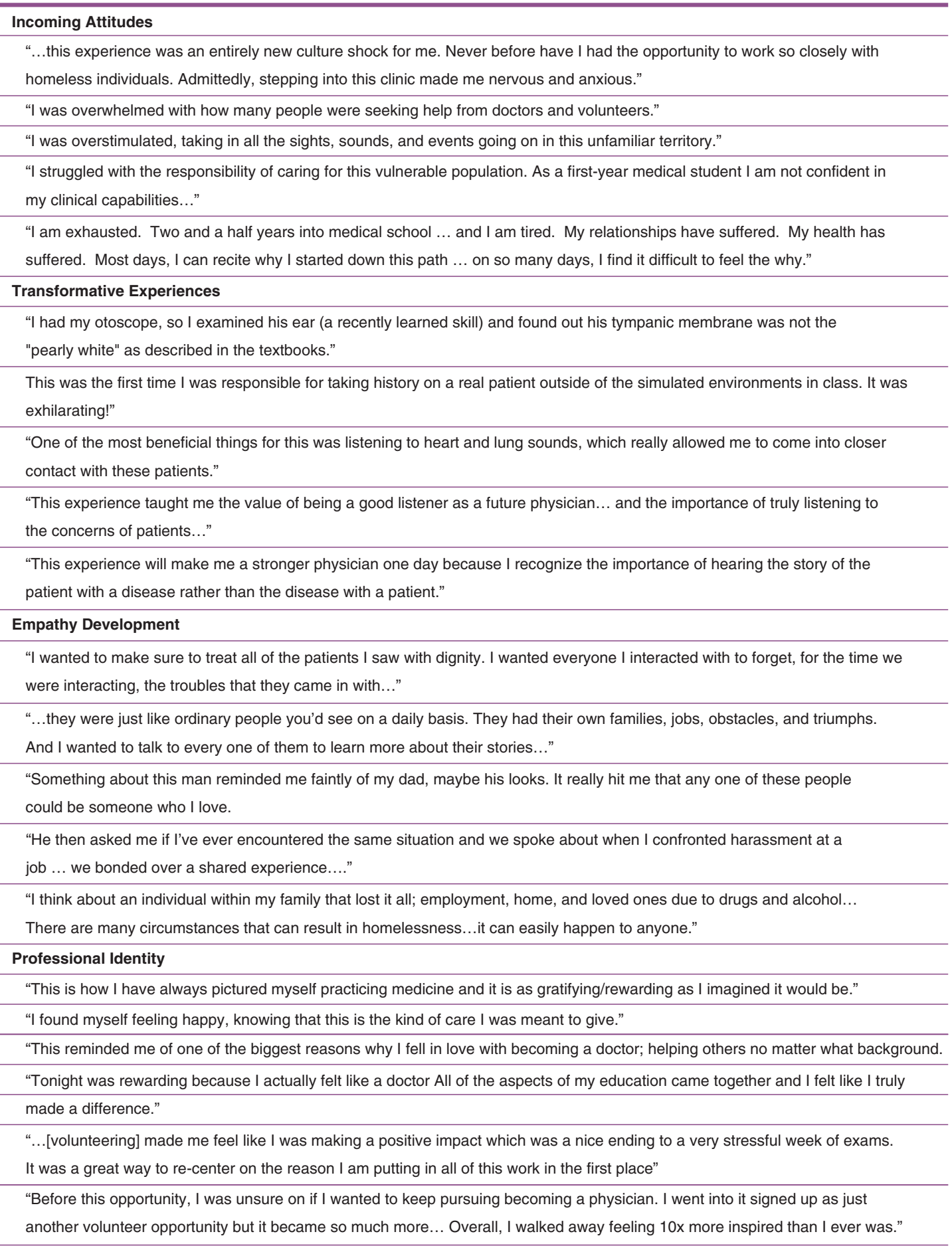

Figure 2.

A sample of students' responses from their reflective essays that described their incoming attitudes, transformative experiences, empathy development, and professional identity. 
models of professional identity development highlight the importance of socializing with patients, fellow students, and instructors to form a healthy professional identity. ${ }^{16,20,23,24}$ Volunteering at a student-run free clinic offered students the opportunity for interaction on all social planes necessary for professional identity development through the coordination of team-based care. With the progression of education, experiences, and career status, new professional identities are created. $^{21,44}$ Students remarked that the wide array of experiences encountered at the clinic challenged their previously held attitudes about patients who are homeless, their profession, and their identities as students. This finding demonstrates that the mechanism for challenging and reforming professional identities is present and inherent to this form of volunteer service.

Our study was limited by both the size and selection of the participants. Students were from a limited geographic area and represented only a percentage of medical students in that area. Additionally, the service learning activities took place at 1 location with a particular model of care, which could limit the generalization of these findings. Student participation was voluntary, and results may have been affected by selfselection bias. Further, qualitative methods are subjective to the biases of the individual coder and the quality of reflection provided by students. We attempted to mitigate these factors by using a set coding schema in our analysis to prevent subjective biasing of the coding. Explicit instruction from the program director on how to complete a reflection and guided verbal group debriefings helped to elevate the quality of student reflective essays, allowing for more robust qualitative analysis. As an observational qualitative study with no control group, the reported outcomes cannot be definitively attributed solely to student participation in this program. Further cohort studies may strengthen these findings by comparing results with a control group who did not participate in a service learning program or reflective exercises. A pre- and postanalysis using a quantitative measure of empathy and professional identity would also further reinforce the conclusions of this study.

\section{Conclusion}

Our analysis revealed that a structured service learning experience providing team-based medical care to patients who were homeless played a role in the development of an empathetic professional identity in medical students in the preclinical stages of their education. In their reflections, students reported a number of transformative experiences, such as learning a new clinical skill, performing OMT, receiving mentoring from resident and attending physicians, having physical contact with patients, working collaboratively with classmates, and engaging in motivating conversations. As described in the reflections, students personally related to patient experiences. Ultimately, this experience humanized the relationship between patient and student doctor, thus eliciting an empathetic response from the students in relation to their patients. Through this analysis of student essays, we conclude that this form of volunteer service challenges incoming attitudes through transformative experiences that lead to empathy development and the formation of a professional identity. We assert that empathy development is a critical step to form a professional identity as a physician.

\section{Author Contributions}

Both authors provided substantial contributions to conception and design, acquisition of data, or analysis and interpretation of data; both authors drafted the article or revised it critically for important intellectual content; both authors gave final approval of the version of the article to be published; and both authors agree to be accountable for all aspects of the work in ensuring that questions related to the accuracy or integrity of any part of the work are appropriately investigated and resolved.

\section{References}

1. Ferrari ND III, Cather GA. Community service, learning and the medical student. Educ Health. 2002;15(2):222-227. doi:10.1080/ 13576280210133044

2. Simpson SA, Long JA. Medical student-run health clinics: important contributors to patient care and medical education. $J$ Gen Intern Med. 2007;22(3):352-356. doi:10.1007/s11606-006-0073-4

3. Smith SD, Johnson ML, Rodriguez N, Moutier C, Beck E. Medical student perceptions of the educational value of a student-run free clinic. Fam Med. 44(9):646-649.

4. Batra P, Chertok JS, Fisher CE, Manseau MW, Manuelli VN, Spears J. The Columbia-Harlem Homeless Medical Partnership: a new model 
for learning in the service of those in medical need. $J$ Urban Health. 2009;86(5):781-790. doi:10.1007/s11524-009-9386-z

5. Beck E. The UCSD Student-Run Free Clinic Project: transdisciplinary health professional education. $J$ Health Care Poor Underserved. 2005;16(2):207-219. doi:10.1353/hpu.2005.0026

6. Eckenfels EJ. Contemporary medical students' quest for self-fulfillment through community service. Acad Med. 1997;72(12):1043-1050.

7. Jain S, Buchanan D. A curriculum in homeless health care was effective in increasing students' knowledge. Med Educ. 2003;37 (11):1032. doi:10.1046/j.1365-2923.2003.01657.x

8. Beck J, Chretien K, Kind T. Professional identity development through service learning: a qualitative study of first-year medical students volunteering at a medical specialty camp. Clin Pediatr (Phila). 2015;54 (13):1276-1282. doi:10.1177/0009922815571108

9. Ross PT, Williams BC, Doran KM, Lypson ML. First-year medica students' perceptions of physicians' responsibilities toward the underserved: an analysis of reflective essays. J Natl Med Assoc Wash. 2010;102(9):761-765. doi:10.1016/s0027-9684(15)30672-6

10. Chrisman-Khawam L, Abdullah N, Dhoopar A. Teaching health-care trainees empathy and homelessness IQ through service learning, reflective practice, and altruistic attribution. Int $J$ Psychiatry Med. 2017;52(3):245-254. doi:10.1177/0091217417730288

11. Davenport BA. Witnessing and the medical gaze: how medical students learn to see at a free clinic for the homeless. Med Anthropol Q. 2008;14(3):310-327. doi:10.1525/maq.2000.14.3.310

12. Sick B, Zhang L, Weber-Main AM. Changes in health professional students' attitudes toward the underserved: impact of extended participation in an interprofessional student-run free clinic. $J$ Allied Health. 2017;46(4):213-219.

13. Masson $\mathrm{N}$, Lester $\mathrm{H}$. The attitudes of medical students towards homeless people: does medical school make a difference? Med Educ. 2003;37(10):869. doi:10.1046/j.1365-2923.2003.01625.x

14. O'Toole TP, Hanusa BH, Gibbon JL, Boyles SH. Experiences and attitudes of residents and students influence voluntary service with homeless populations. J Gen Intern Med. 14(4):211-216. doi:10.1046/ j.1525-1497.1999.00319.x

15. Smith SD, Yoon R, Johnson ML, Natarajan L, Beck E. The effect of involvement in a student-run free clinic project on attitudes toward the underserved and interest in primary care. $J$ Health Care Poor Underserved. 2014;25(2):877-889. doi:10.1353/hpu.2014.0083

16. Cruess RL, Cruess SR, Boudreau JD, Snell L, Steinert Y. A schematic representation of the professional identity formation and socialization of medical students and residents: a guide for medical educators. Acad Med. 2015;90(6):718-725. doi:10.1097/ACM.0000000000000700

17. Goldie J. The formation of professional identity in medical students: considerations for educators. Med Teach. 2012;34(9):e641-e648. doi:10.3109/0142159X.2012.687476

18. Holden M, Buck E, Clark M, Szauter K, Trumble J. Professional identity formation in medical education: the convergence of multiple domains. HEC Forum. 2012;24(4):245-255. doi:10.1007/ s10730-012-9197-6

19. Miller E, Balmer D, Hermann N, Graham G, Charon R. Sounding narrative medicine: studying students' professional identity development at Columbia University College of Physicians and Surgeons. Acad Med. 2014;89(2):335-342. doi:10.1097/ ACM.0000000000000098
20. Niemi PM. Medical students' professional identity: self-reflection during the preclinical years. Med Educ. 1997;31(6):408-415. doi:10.1046/ j.1365-2923.1997.00697.x

21. Pratt MG, Rockmann KW, Kaufmann JB. Constructing professional identity: the role of work and identity learning cycles in the customization of identity among medical residents. Acad Manage $\mathrm{J}$. 2006;49(2):235-262.

22. Stern DT, Papadakis M. The developing physician—becoming a professional. N Engl J Med. 2006;355(17):1794-1799. doi:10.1056/ NEJMra054783

23. Weaver R, Peters K, Koch J, Wilson I. "Part of the team": professional identity and social exclusivity in medical students. Med Educ. 2011;45(12):1220-1229. doi:10.1111/j.1365-2923.2011.04046.x

24. Haidet $P$, Stein HF. The role of the student-teacher relationship in the formation of physicians. J Gen Intern Med. 21(S1):S16-S20. doi:10.1111/j.1525-1497.2006.00304.x

25. Haider SI, Snead DRJ, Bari MF. Medical students' perceptions of clinical teachers as role model. PLoS One. 2016;11(3):1-9. doi:10.1371/journal.pone. 0150478

26. Passi V, Johnson N. The impact of positive doctor role modeling. Med Teach. 2016;38(11):1139-1145. doi:10.3109/ 0142159X.2016.1170780

27. Wilson I, Cowin LS, Johnson M, Young H. Professional identity in medical students: pedagogical challenges to medical education. Teach Learn Med. 2013;25(4):369-373. doi:10.1080/10401334.2013.827968

28. Cruess RL, Cruess SR, Boudreau JD, Snell L, Steinert Y. Reframing medical education to support professional identity formation. Acad Med. 2014;89(11):1446-1451. doi:10.1097/ ACM.0000000000000427

29. Brazeau CM, Schroeder R, Rovi S, Boyd L. Relationships between medical student burnout, empathy, and professionalism climate. Acad Med. 2010;85(10):S33-S36. doi:10.1097/ACM.0b013e3181ed4c47

30. Teherani A, Hodgson CS, Banach M, Papadakis MA. Domains of unprofessional behavior during medical school associated with future disciplinary action by a state medical board. Acad Med. 2005; 80(10 suppl):S17-S20. doi:10.1097/00001888-200510001-00008

31. Crandall SJ, Davis SW, Broeseker AE, Hildebrandt C. A longitudinal comparison of pharmacy and medical students' attitudes toward the medically underserved. Am J Pharm Educ. 2008;72(6):148. doi:10.5688/aj7206148

32. Crossley J, Vivekananda-Schmidt P. The development and evaluation of a professional self-identity questionnaire to measure evolving professional self-identity in health and social care students Med Teach. 2009;31(12):e603-e607. doi:10.3109/ 01421590903193547

33. Costa P, Alves R, Neto I, Marvão P, Portela M, Costa MJ. Associations between medical student empathy and personality: a multi-institutional study. PLoS One. 2014;9(3):e89254. doi:10.1371/ journal.pone.0089254

34. Fields SK, Mahan P, Tillman P, Harris J, Maxwell K, Hojat M. Measuring empathy in healthcare profession students using the Jefferson Scale of Physician Empathy: health provider-student version. J Interprof Care. 2011;25(4):287-293.

35. Hojat M, Gonnella JS, Mangione S, et al. Empathy in medical students as related to academic performance, clinical competence and gender. Med Educ. 2002;36(6):522-527. 


\section{MEDICAL EDUCATION}

36. Hojat M. Empathy in Health Professions Education and Patient Care. Springer International Publishing; 2016.

37. Berg K, Blatt B, Lopreiato J, et al. Standardized patient assessment of medical student empathy: ethnicity and gender effects in a multi-institutional study. Acad Med. 2015;90(1):105-111. doi:10.1097/ ACM. 0000000000000529

38. Chen D, Lew R, Hershman W, Orlander J. A cross-sectional measurement of medical student empathy. J Gen Intern Med. 2007;22 (10):1434-1438. doi:10.1007/s11606-007-0298-x

39. Chen DCR, Kirshenbaum DS, Yan J, Kirshenbaum E, Aseltine RH Characterizing changes in student empathy throughout medical school. Med Teach. 2012;34(4):305-311. doi:10.3109/0142159X.2012.644600

40. Hojat M, Mangione S, Nasca TJ, et al. An empirical study of decline in empathy in medical school. Med Educ. 2004;38(9):934-941.

41. Hojat M, Vergare MJ, Maxwell K, et al. The devil is in the third year: a longitudinal study of erosion of empathy in medical school. Acad Med. 2009;84(9):1182-1191. doi:10.1097/ACM.0b013e3181b17e55

42. Brazeau CM, Schroeder R, Rovi S, Boyd L. Relationship between medical student service and empathy. Acad Med. 2011;86(10): S42-S45. doi:10.1097/ACM.0b013e31822a6ae0

43. Thomas MR, Dyrbye LN, Huntington JL, et al. How do distress and well-being relate to medical student empathy? a multicenter study.
J Gen Intern Med. 2007;22(2):177-183. doi:10.1007/ s11606-006-0039-6

44. Smith SE, Tallentire VR, Cameron HS, Wood SM. The effects of contributing to patient care on medical students' workplace learning. Med Educ. 2013;47(12):1184-1196. doi:10.1111/medu.12217

45. Hojat M, Shannon SC, DeSantis J, Speicher MR, Bragan L, Calabrese LH. Empathy in medicine national norms for the Jefferson scale of empathy: a nationwide project in osteopathic medical education and empathy (POMEE). J Am Osteopath Assoc. 2019;119(8):520-532. doi:10.7556/jaoa.2019.091

46. Kimmelman M, Giacobbe J, Faden J, Kumar G, Pinckney CC, Steer R Empathy in osteopathic medical students: a cross-sectional analysis. J Am Osteopath Assoc. 2012;112(6):347-355. doi:10.7556/ jaoa.2012.112.6.347

47. Martingano AJ, Martingano D. Measuring multidimensional empathy: theoretical and practical considerations for osteopathic medical researchers. J Am Osteopath Assoc. 2017;117(11):697-704. doi:10.7556/jaoa.2017.136

48. McTighe AJ, DiTomasso RA, Felgoise S, Hojat M. Effect of medical education on empathy in osteopathic medical students. $J \mathrm{Am}$ Osteopath Assoc. 2016;116(10):668-674. doi:10.7556/jaoa.2016.131

() 2020 American Osteopathic Association

\section{Rapid Review}

The Journal of the American Osteopathic Association considers manuscripts for rapid review when appropriate. Authors must justify their rapid review requests in their cover letters. Rapid review is reserved primarily for original contributions and reviews of high importance to the osteopathic medical profession. However, the editor in chief will assess each rapid review request on a case-by-case basis. For more information on submitting manuscripts to the JAOA, visit http://jaoa.org/ss/mssubmission.aspx. 